\begin{tabular}{lll}
\hline Vol 6. & Dezembro de 1958 & N.० 2 \\
\hline
\end{tabular}

\title{
CÂNDIDO MARIANO DA SILVA RONDON
}

\author{
Darcy Ribeiro \\ Professor da Universidade do Brasil, Rio de Janeiro
}

Em sua última viagem a Mato Grosso. Rondon fêz uma visita ao velho Cadete, chefe dos índios Borôr. Foi um encontro singular de amigos que se conheciam há mais de sessenta anos, desde quando Rondon, no princípio de sua carreira militar e indigenista, chamou ao nosso convívio os Borôro de Garças.

Os dois velhos tomaram-se as mãos e, meio abraçados, falaram longamente na língua daquêles índios. A certa altura, Rondon voltou-se para alguém que o acompanhava e indagou:

- Sabe o que êle está dizendo? Me aconselha a vir morrer aqui, porque, diz êle, estando velho, não durarei muito e só os Borôro saberiam fazer o meu entêrro.

Pouco tempo depois estivemos em Mato Grosso para orientar a documentação cinematográfica dos cerimoniais fúnebres de Cadete. Reunira-se tôda a tribo para aquela homenagem e muitos índios me perguntaram quando viria Rondon. Só se convenceram de que não compareceria ao ouvirem a gravação que leváramos, em que Rondon lhes dizia que íamos como seus olhos e seus ouvidos, para tudo ver' e tudo ouvir, a fim de contar-lhe depois. Que êle estava velho e cansado, só por isto não ia também à despedida de Cadete. Graças a esta gravação pudemos não apenas assistir, mas também documentar em todos os seus detalhes, momentos do cerimonial que, até então, sòmente índios haviam presenciado.

Acompanhei os funerais de Rondon no Rio, sei das homenagens que the foram prestadas em todo o país e como a notícia do seu falecimento repercutiu nas aldeias indígenas. O Brasil o perdeu consciente cle que perdia a personalidade mais enérgica e mais generosa que nosso povo jamais produziu. Mas, ainda me pergunto se Cadete, de certo modo, não teria razão. Tanto quanto filhos podem chorar aos pais, os índios o chorariam, conscientes do grande vazio que se abre com sua morte, dos perigos que, doravante, pesam sôbre suas vidas e suas terras, tantas vêzes ameaçadas em têrmos de se não fôsse êsse Rondon...

Ainda hoje poucos se capacitaram de que o amparo ao índio seja uma política oficial do govêrno, uma exigência da opinião pública, uma imposição da lei e não apenas o fruto da obstinação de um homem, de Rondon. O seu devotamento de mais de meio século à causa indígena fêz dêle a personificação mesma desta causa. Colocando a serviço dela 
seu prestigio pessoal, duramente conquistado, de grande engenheiro construtor de linhas telegráficas e de promotor das mais amplas pesquisas geográficas, geológicas, antropológicas, faunísticas e florísticas empreendidas em nosso país, êle conseguiu mais do que qualquer outro poderia alcançar.

Graças a Rondon, sobrevivem hoje dezenas de milhares de índios que teriam perecido sem o amparo que êle fêz chegar às suas aldeias longínquas.

E' a vida e a liberdade dêstes índios que se encontra, agora, sob ameaça e exige, para que sejamos dignos de Rondon, uma outra ordem de homenagem à sua memória: a vigilância mais alerta para as tentativas, que fatalmente virão, de morte e de esbulho contra os índios e a ação mais enérgica para denunciá-las e impedi-las .

Quando Rondon iniciou sua carreira indigenista, nos primeiros anos dêste século, conflitos sangrentos entre índios e civilizados lavravam por todo o país. Entregues a seu próprio destino, os índios eram dizimados por uma sociedade dotada de recursos infinitamente superiores que crescera em seu próprio território. Sua só existência era motivo de inquietação e clamor. E quando acrescia uma circunstância qualquer, como o valor econômico das terras que ocupavam, ou de si próprios como mão de obra, era a condenação ao extermínio.

Os que se opunham à expansão das frentes pioneiras que avançavam sôbre suas aldeias, eram dizimados. Muitas vêzes por chacinadores profissionais, os tristemente célebres bugreiros estipendiados pelos governos estaduais. Ainda mais dramático era o destino dos que se haviam sub. metido ao nosso convívio, já incapazes de defender-se, experimentavam condições de penúria às quais nenhum povo poderia sobreviver.

Assim viviam, assim morriam os índios do Brasil em 1910. E isto não ocorria apenas em igarapés ignorados da Amazônia ou nos ermos do Brasil Central, mas às portas ou à distância de um dia de viagem, de cidades como São Paulo, Blumenau, Vitória e Ilhéus.

Enquanto a gente das cidades via o índio como o personagem de ro. mance idílico, ao gôsto de José de Alencar, ou o herói épico à Gonçalves Dias, inspirados em Rousseau ou em Chateaubriand, no interior, o índio de verdade era propositadamente contaminado de varíola, envenenado a estriquinina ou espingardeado.

A tomada de consciência, o desmascaramento desta contradição se deve a Rondon. Foi êle que, trazendo dos sertões de Mato Grosso uma imagem nova e verdadeira do índio, substituiu a figura de Peri pela de um Nambikuára aguerrido e altivo, ou dos Kepkiriwát encantados pelos instrumentos super-cortantes da civilização, ou ainda, dos Umotína, dos Ofaié e tantos outros, levados a extremos de penúria pela perseguição in- 
clemente que thes moviam, mas, ainda assim, fazendo comoventes esforços para confraternizar com o branco.

Depois das jornadas de Rondon, da vitória prática dos seus métodos persuasórios junto a grupos aguerridos como os Nambikuára, não podiam manter-se mais as velhas teses defendidas por tantos, da incapacidade do Índio para a civilização, da inevitabilidade do uso da fôrça contra o índio arredio e hostil e, ainda, a conjura mais manhosa, de que a dizimação dos povos tribais, conquanto lastimável, seria uma imposição do progresso nacional e, assim, històricamente inexorável.

Em nome da falácia cientificista escamoteada nesta proposição, prow curava-se explicar por graves razões históricas, por imperativos da natureza, o que não passava da cobiça de bandos celerados que avançavam mata-a-dentro em busca de seringais ou castanhais, sempre prontos a exterminar o índio com que deparassem; de criadores que varriam o índio dos campos a ferro-e-fogo para destiná-los a seu gado; de colonos que se empenhavam em ocupar e usurpar terras em que viviam índios deste sempre e eram indispensáveis à sua sobrevivência.

Através de uma vida inteira de dedicação, Rondon se fêz o mais sábio e o mais vigilante servidor da causa indígena. Seus quatro princípios constituem, hoje, um legado da cultura brasileira que nos cabe respeitar e fazer cumprir.

O primeiro princípio de Rondon, Morrer, se preciso fôr, matar, nunca, foi formulado no comêço dêste século, quando, devassando os sertões impenetrados de Mato Grosso ia de encontro às tribos mais aguerridas com palavras e gestos de paz, negando-se a revidar seus ataques, por entender que êle e sua tropa eram os invasores e, como tais $s_{1}$ se fariam criminosos, se de sua ação resultasse a morte de um índio.

Quando há alguns anos nos referimos a êste princípio numa conferência internacional, fomos procurados pelo representante da India, que indagou se era Rondon um discípulo de Gandhi. Esta pergunta vale por um julgamento da altitude que alcança o pensamento pacifista brasileiro, formulado por Rondon.

O segundo princípio é o do respeito às tribos indígenas como povos independentes que, apesar de sua rusticidade e por motivo dela mesma, têm o direito de ser êles próprios, de viver suas vidas, de professar suas crenças e de evoluir, segundo o ritmo de que sejam capazes, sem estar sujeitos a compulsões de qualquer ordem e em nome de quaisquer princípios.

Num tempo em que se presencia a dizimação em massa dos Kikúyo por tropas imperiais inglêsas, na defesa dos interêsses de colonos que se instalaram nas terras daqueles povos, nenhum princípio é mais atual.

O terceiro princípio de Rondon é o de garantir aos índios a posse das terras que habitam e são necessárias à sua sobrevivência. Neste caso não 
precisamos, lamentàvelmente, buscar exemplos na África. Até hoje êste princípio, embora inscrito na Constituição Brasileira, é, ali, apenas uma frase eloqüente. Por não ter sido ainda regulamentado, também não é cumprido. Entre dezenas de exemplos possíveis citaremos os Xavánte, que são hoje, jurìdicamente falando, invasores das terras em que sempre viveram, pois elas estão sendo concedidas em enormes glebas aos que têm maior capacidade de convencer ao poder público.

O quarto princípio de Rondon é assegurat aos índios a proteção direta do Estado, não como um ato de caridade ou de favor, mas como um direito que lhes assiste por sua incapacidade de competir com a sociedade, dotada de tecnologia muito superior, que se instalou sôbre seu território.

A luta para realizar êste princípio começou para Rondon em 1910 com a criação do Serviço de Proteção aos Índios e custou o melhor de suas energias. Entretanto, é preciso que se diga, nestes mesmos anos, em virtude da carência dos recursos destinados a esta obra, da falta de compreensão e de apoio por parte das autoridades mais responsáveis do país, da incapacidade daquele Serviço para colocar-se à altura da tarefa que é chamado a realizar, apesar do zêlo e da combatividade de Rondon, desapareceram - não assimilados na população nacional, mas simplesmente por morte, por extinção - mais de 80 grupos indígenas. Se tamanha mortandade foi possível estando vivo o grande paladino da causa indígena, o que sucederá agora, apagada sua vigilância, esgotada sua energia, emudecida sua voz?

$\mathrm{Na}$ verdade, o que foi até hoje a obra de um homem, tem de ser, doravante, a responsabilidade de todo o povo brasileiro. Êste é o legado de Rondon.

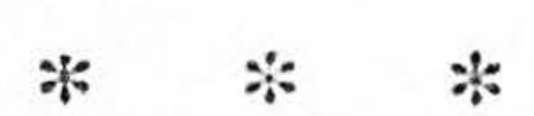

\section{BIBLIOGRAFIA DE CÂNDIDO MARIANO DA SILVA RONDON}
1910 - Etnografia - Anexo n. 5 ao Relatório da Comissão de Linhas Telegráficas e Estratégicas de Mato Grosso ao Amazonas - Rio de Janeiro, 57 pgs. em $4 .^{\circ}$.

1912 - O Serviço de Proteção aos índiós e Localização de Trabalhadores Nacionais. Rio de Janeiro, 10 pgs.

1915 - Relatório Geral sôbre a Comissão das Linhas Telegráficas e Estratégicas de Mato Grosso ao Amazonas. Rio de Janeiro, vol. I, 365 pgs. in $4 .^{\circ}$, mapas e pranchas; vols. IV e V (1949), 334 pgs., 5 mapas, gráficos e fotografias.

1916 - Conferências realizadas no Teatro Phoenix do Rio de Janeiro em Outubro de 1915 sôbre os trabalhos da Expedição Roosevelt e da Comissão de Linhas Telegráficas e Estratégicas de Mato Grosso ao Amazonas. Rio de Janeiro, XVII, 266 pgs. in $8 .^{\circ}, 20$ pranchas e 4 mapas. (Versão inglêsa em 1916). 
1922 - Conferências realizadas em 1910 no Rio de Janeiro e São Paulo. Rio de Janeiro, 122 pgs. in $80^{\circ}, 14$ pranchas (2a. edição, 1946).

1938 - Discurso pronunciado na sessão cívica organizada pelo Ministro das Relações Exteriores, Dr. Oswaldo Aranha, para comemorar o regresso do Presidente da Comissão Mista Internacional PeruColômbia. Rio de Janeiro, 15 pgs.

1940 - Rumo ao Oeste - Rio de Janeiro.

1940 - "A Etnografia do Brasil em revista" - Revista Brasileira de Geografia, vol. II, n. ${ }^{\circ}$ 4, Rio de Janeiro, pgs. 594-621 (2a. edição em 1944, 3a. edição em 1946).

1940 - José Bonifácio e o Problema Indígena - Revista do Instituto Histórico e Geográfico Brasileiro, vol. CLXXIV, pgs. 867-893.

1943 - Problema Indígena - Separata do relatório da Comissão Mista Peru-Colômbia. América Indígena, vol. III, n. 1 - México, pgs. 23-37. Em colaboração com Antônio Pirineus de Souza.

1943 - Mapa do Levantamento expedito do rio Juru, afluente do GyParaná. Rio de Janeiro, impresso em 3 côres com $1,56 \times 0,45$, escala $1: 100.000$.

$1946 /$

1955 - Índios do Brasil - Rio de Janeiro. Volume I - Centro, Noroeste e Sul de Mato Grosso (1946), 366 pgs. in 8. ${ }^{\circ}, 573$ figuras; volume II - Cabeceiras do rio Xingu ao Araguaia e Oiapoque (1953), 363 pgs. in 8., 401 figuras; volume III - Norte do Rio Amazonas (1955), 370 pgs. in $8 .^{\circ}, 540$ figuras.

Em colaboração com João Barbosa de Faria:

1948 - Glossário Geral das Tribos Silvícolas de Mato Grosso e outras da Amazônia e do Norte do Brasil. Rio de Janeiro, 257 pgs. in $8 .^{\circ}, 11$ mapas.

1948 - Esbóço gramatical e Vocabulário da Língua dos indios Borôro. Rio de Janeiro, 211 pgs. in $8 .^{\circ}, 3$ pranchas.

1948 - Esbóço gramatical e Vocabulário, Lendas e Cânticos dos índios Arití (Paressi) - Rio de Janeiro, 110 pgs. in 8. .

Em colaboração com o General Jaguaribe Gomes de Mattos:

1952 - Nova Carta de Mato Grosso, impressa a côres, em escala de 1: 1.000 .000 .

\section{SELEÇ̃̃O DA BIBLIOGRAFIA SOBRE RONDON}

BANDEIRA, Alipio

1923 - A Mistificação Salesiana, Rio de Janeiro, 93 pgs.

1926 - A Cruz Indigena - Pôrto Alegre, 131 pgs. 
BADET, Charles

1951 - Charmeur d'Indiens - Le General Rondon, Paris, 226 pgs., fotos e 1 mapa.

BOTELHO DE MAGALHÃES, Amílcar

1941 - Pelos Sertões do Brasil, São Paulo, 2a. edição, 507 pgs. in 8. ${ }^{\circ}, 12$ pranchas e 5 mapas.

1942 - Impressões da Comissão Rondon - São Paulo, 5a. edição, 445 pgs. in $8 .^{\circ}, 13$ pranchas.

1943 - "O Problema da Civilização dos índios to Brasil" - América Indigena, vols. III e IV - México.

1947 - Indios do Brasil - Separata de América Indigena, México, 96 pgs. in $8 .^{\circ}, 10$ figuras.

1956 - A Obra Ciclópica de Rondon - Biblioteca do Exército, Rio de Janeiro, 63 pgs.

BOTELHO DE MAGALHÃES, Amilcar e

MURTA BARBOSA, Luiz Bueno

1916 - Missão Rondon - Rio de Janeiro, 463 pgs. in $8 .^{\circ}, 46$ pranchas.

CONSELHO NACIONAL DE PROTECÃ̃O AOS ÍNDIOS

1946 - Catálogo Geral das Publicações da Comissão Rondon e do Conselho Nacional de Proteção aos Índios - Rio de Janeiro, $34 \mathrm{pgs}$.

CRULS, Gastão

1938 - A Amazônia que eu vi - Rio de Janeiro, 339 pgs. in 8.", 17 pranchas, 1 mapa, bibliografia.

DUARTE, Bandeira

1941 - Rondon, o Bandeirante do Século XX - São Paulo, 204 pgs. GUSMÃO, Clovis de

1942 - Rondon - Livr. José Olímpio, Rio de Janeiro, 226 pgs., fotografias.

HORTA BARBOSA, Luiz Bueno

1919 - O Serviço de Proteção aos Índios e a História da Colonização do Brasil - Rio de Janeiro, 80 pgs. in $8 .^{\circ} 9$ pranchas.

1923 - Pelo índio e sua Proteção Oficial - 71 pgs. in $16 .^{\circ}-27$ pranchas (2a. edição em 1947).

1926 - O Problema Indigena no Brasil - Rio de Janeiro, 31 pgs. in 8. ${ }^{\circ}$ (2a. edição em 1947).

INSTITUTO HISTÓRICO E GEOGRÁFICO DE MATO GROSSO

1940 - O Instituto Histórico e o General Rondon - Tomos XLIIrXLIV da Revista do Instituto Histórico de Mato Grosso Rio de Janeiro, 151 pgs. 
LINS, Ivan

1942 - A obra educativa do General Rondon - Biblioteca Militar Rio de Janeiro.

MAGALHÃES, Basílio de

1925 - Em defesa dos indios de fazendas nacionais - Rio de Jam neiro, 87 pgs. in $80^{\circ}$.

MIRANDA RIBEIRO, Alípio

1945 - A Comissão Rondon e o Museu Nacional - Rio de Janeiro, 2a. edição, 92 pgs. - Cons. Nac. Prot. aos indios.

OFICINA INTERNACIONAL DEL TRABAJO

1945 - Poblaciones Indigenas - Condiciones de vida y de Trabajo de los Pueblos Autóctones de los países independientes. Genebra, 670 pgs., 61 quadros, 10 mapas, 26 ilustrações.

OLIVEIRA, Humberto de

1947 - Coletânéa de Leis, Atos e Memórias Referentes ao Indigena Brasileiro, 229 pgs.

PIBEIRO, Darcy

1953 - "Organização Administrativa do Servico de Proteção aos Índios" - Boletim SPI - 1953, pgs. 1-15.

1954 - "Indian Frontiers in Brazil" - Americas - Revista da União Panamericana, abril de 1954, pgs. 16-18 e 39-40.

1954 - "Nourrir s'il faut, mas ne jamais tuer" - Le Courrier de l'UNESCO, n.'s 8-9 de 1954, pgs. 8-9 e 12-13.

ROOSEVELT, Theodore

1914 - Through the Brazilian Wilderness - London, 2a. edição, N. York (1925), XI, 410 pgs., 8 pranchas, 3 mapas. Tradução brasileira de Conrado Erichsen - Através dos Sertões do Brasil - São Paulo, 1944 e de Luiz Guimarães Júnior: Nas Selvas sdo Brasil, Rio de Janeiro, 1944.

ROQUETTE-PINTO, Edgar

1917 - Rondônia - Vol. XX dos Arquivos do Museu Nacional - Rio de Janeiro, 250 pgs. in $8 .^{\circ}, 30$ gravuras, 1 mapa, 12 fonogramas, índice e glossário. Terceira edição brasileira em 1935; 1a. edição alemã, em Viena (1954), tradução de Etta Becker Donner.

VIVEIROS, Esther de

1958 - Rondon conta sua vida - New York (Robert Speller) e Rio de Janeiro (Livraria São José), 638 pgs. in $8 .^{\circ}$. 